\title{
SUPERAÇÃO DE DORMÊNCIA EM SEMENTES DE Tachigali myrmecophila
}

(Ducke) Ducke

Denise Siqueira Pereira1, Denmora Gomes de Araujo², Pedro Henrique Oliveira $\underline{\text { Simões }}^{3}$, Lenilson Ferreira Palheta ${ }^{3}$, Ruy Guilherme Correia ${ }^{4}$

1 Graduanda em Agronomia. Universidade Federal Rural da Amazônia, Belém-PA. 2 Professora Doutora da Universidade Federal Rural da Amazônia, Belém-PA. 3 Mestrando em Ciências Florestais, Universidade Federal Rural da Amazônia, Belém-PA (e-mail: simoes.florestal@gmail.com)

4 Doutorando em Ciências Florestais da Universidade Federal Rural da Amazônia, Belém-PA.

Recebido em: 08/09/2015 - Aprovado em: 14/11/2015 - Publicado em: 01/12/2015 DOI: http://dx.doi.org/10.18677/Enciclopedia_Biosfera_2015_228

\begin{abstract}
RESUMO
Objetivou-se avaliar diferentes métodos de superação de dormência de sementes para potencializar a propagação de Tachigali myrmecophila (Ducke) Ducke. Foram realizados cinco tratamentos: testemunha - fazendo-se apenas a assepsia das sementes por meio da imersão em hipoclorito de sódio (2\%) por cinco minutos; escarificação mecânica - assepsia das sementes por meio da imersão em hipoclorito de sódio ( $2 \%$ ) por cinco minutos e abrasão da superfície da semente à lixa no 80, no lado oposto à micrópila das sementes, para não danificar o embrião; imersão em ácido sulfúrico (98\% p.a.) por 10 ou 20 minutos e imersão em água assepsia das sementes por meio da imersão em hipoclorito de sódio (2\%) por 5 minutos e imersão em água por 24 horas. Empregou-se o delineamento inteiramente casualizado, sendo cinco tratamentos e quatro repetições. Cada parcela foi composta por 25 sementes. Os tratamentos de escarificação mecânica com lixa no 80 e imersão em ácido sulfúrico por 20 minutos proporcionam maior vigor na emergência e crescimento de plântulas. Para a produção de mudas da espécie, recomenda-se a escarificação mecânica das sementes com lixa, pelo bom resultado de emergência e por dispensar a utilização do ácido sulfúrico.
\end{abstract}

PALAVRAS-CHAVE: Escarificação; espécie florestal; emergência; plântulas.

\section{OVERCOMING DORMANCY IN SEEDS OF Tachigali myrmecophila (Ducke) Ducke}

\begin{abstract}
Aimed to evaluate different methods of overcoming seed dormancy to enhance the spread of Tachigali myrmecophila (Ducke) Ducke. Five treatments were performed: control - making themselves only asepsis of seeds by soaking in sodium hypochlorite $(2 \%)$ for five minutes; chiseling - asepsis of seeds by soaking in sodium hypochlorite $(2 \%)$ for five minutes and seed surface abrasion sandpaper No. 80 on the side opposite to the micropyle seeds, to avoid damage to the embryo; immersion in sulfuric acid ( $98 \%$ pa) for 10 or 20 minutes and immersion in water - asepsis of seeds by soaking in sodium hypochlorite $(2 \%)$ for 5 minutes and immersion in water for 24
\end{abstract}


hours. He used a completely randomized design, with five treatments and four replications. Each plot consisted of 25 seeds. The mechanical scarification treatments with sandpaper No. 80 and immersion in sulfuric acid for 20 minutes provide greater effect on the emergence and growth of seedlings. For the production of seedlings of the species, it is recommended that the mechanical scraping of seeds with sandpaper, the good results and emergency waive the use of sulfuric acid.

KEYWORDS: Scarification; forest species; emergency; seedlings.

\section{INTRODUÇÃO}

A espécie Tachigali myrmecophila (Ducke) Ducke, pertencente a subfamília Caesalpinioideae, é conhecida na região norte pelos nomes vulgares de tachi-preto, tachi, tachi-pitomba e tachizeiro (RIBEIRO, 1999) e está inserida no grupo ecológico de espécies intolerantes à sombra (CARVALHO et al., 2004). Segundo VAN DER WERFF (2008), são árvores de grande porte, chegando a atingir até $45 \mathrm{~m}$ de altura e possui madeira de densidade média.

A espécie tem sido pouco explorada pelos produtores, mas eventualmente é utilizada para a produção de carvão (SOUZA FILHO et al., 2005). De acordo com SANTOS et al. (2007), devido ao crescimento rápido e a capacidade de fixação de nitrogênio, T. myrmecophila possui potencial para ser adotada na formação de sistemas agroflorestais. Esta espécie ocorre em toda a região amazônica, comumente nas matas de terra firme (SANTOS et al., 2007).

A necessidade de restaurar o ambiente natural tem estabelecido um aumento na demanda por mudas pertencentes a espécies florestais nativas (SILVA et al., 2014). A maioria destas espécies são dispersas por sementes e o sucesso na formação de mudas depende do conhecimento sobre o processo de germinação das sementes dessas espécies, bem como a qualidade da semente utilizada (REGO et al., 2009). No entanto, de acordo com ROLSTON (1978), o tegumento impermeável é o mecanismo mais comum de dormência em sementes de leguminosas tropicais, podendo atingir até $98 \%$ dessas espécies.

O uso de mecanismos de superação de dormência acelera o processo de germinação e aumenta a porcentagem germinativa, assim como a uniformidade e sobrevivência das plântulas. O fator limitante para a aplicação e eficiência desses tratamentos consiste na variabilidade do grau de dormência entre as sementes, que pode variar entre espécies e entre sementes do mesmo fruto (CARVALHO \& NAKAGAWA, 2012). Entre os tratamentos utilizados com sucesso para superação da dormência tegumentar de espécies florestais, destacam-se as escarificações mecânicas e químicas, imersão das sementes em água quente (OLIVEIRA et al., 2003), tratamentos com ácidos e bases fortes, pré-resfriamento, entre outros (BRASIL, 2009).

Diante do exposto, objetivou-se avaliar diferentes métodos de superação de dormência de sementes para potencializar a propagação de T. myrmecophila (Ducke) Ducke.

\section{MATERIAL E MÉTODOS}

As sementes utilizadas foram procedentes de 10 matrizes localizadas na Ilha de Germoplasma, Reservatório do município de Tucuruí, estado do Pará, posicionada geograficamente a 351'58,3"S e 4938'25,8"W.

Utilizaram-se os seguintes tratamentos na superação de dormência: testemunha - fazendo-se apenas a assepsia das sementes por meio da imersão em hipoclorito de sódio (2\%) por cinco minutos; escarificação mecânica - assepsia 
das sementes por meio da imersão em hipoclorito de sódio (2\%) por cinco minutos e abrasão da superfície da semente à lixa no 80 , no lado oposto à micrópila das sementes, para não danificar o embrião; imersão em ácido sulfúrico ( $98 \%$ p.a.) por 10 ou 20 minutos e imersão em água - assepsia das sementes por meio da imersão em hipoclorito de sódio (2\%) por 5 minutos e imersão em água por 24 horas. Desta forma, empregou-se o delineamento inteiramente casualizado, sendo cinco tratamentos e quatro repetições. Cada parcela foi composta por 25 sementes.

Considerando-se especificamente a escarificação em ácido sulfúrico, as sementes foram inseridas em Becker com um volume de $\mathrm{H}_{2} \mathrm{SO}_{4}$ suficiente para cobri-las. Posteriormente, a cada tempo de imersão, as sementes foram dispostas em peneira metálica para lavagem com água destilada por 15 minutos.

O experimento foi conduzido em bandejas plásticas $(6,3 \times 29 \times 37 \mathrm{~cm})$, utilizando-se como substratos areia e serragem esterilizada, na proporção 1:1. As bandejas foram mantidas em câmara de germinação do tipo B.O.D a $30{ }^{\circ} \mathrm{C}$ com fotoperíodo de 12 horas. A contagem das plântulas emergidas ocorreu diariamente, por um período de 20 dias.

Foi realizada a determinação do grau de umidade das sementes, segundo o método de estufa a 105ㄷ (BRASIL, 2009). Os parâmetros analisados, decorrentes das contagens diárias das plântulas emergidas, foram: percentagem de emergência (\%E); índice de velocidade de emergência (IVE) e; tempo médio de emergência (TME). Para a contagem das plântulas emergidas, foi considerada a emissão de qualquer parte da plântula acima do substrato.

Os dados foram submetidos a testes de normalidade (Kolmogorov-Smirvov e Shapiro-Wilk) e foi constatada a não normalidade na distribuição dos dados. Dessa forma, os resultados das porcentagens de emergência (\%E) foram transformados utilizando-se a equação arco seno $(\% \mathrm{E} / 100)^{1 / 2}$, para aproximação da distribuição normal da população (SANTANA \& RANAL, 2004).

As plântulas, logo após o término da contagem de emergência, foram acondicionadas em sacos de papel e submetidas a secagem pelo método de estufa (65 ํㅡ, 24 h) para determinação da massa de matéria seca de parte aérea e sistema radicular.

Os dados obtidos foram submetidos à análise de variância e as causas de variação significativas foram comparadas pelo teste de Tukey $(p<0,05)$.

\section{RESULTADOS E DISCUSSÃO}

As sementes do tachi-preto apresentaram 10,3\% de umidade, valor próximo dos encontrados para três espécies florestais do gênero Parkia, Parkia pendula (Willd.) Benth. ex. Walp. (CÂMARA et al., 2008), Parkia velutina Bernoist, 11,3\% (MENDES et al., 2009) e Parkia discolor Spruce ex Benth., 9,8\% (PEREIRA \& FERREIRA, 2010). Após a semeadura, o início da emergência ocorreu no sexto dia para os tratamentos com lixa e ácido sulfúrico por 10 e 20 minutos, no sétimo dia para as sementes imersas em água e no oitavo dia para as sementes sem escarificação. Os resultados encontrados demonstram que os tratamentos que proporcionaram as maiores percentagens de emergência tiveram médias estatisticamente iguais (Figura 1). 


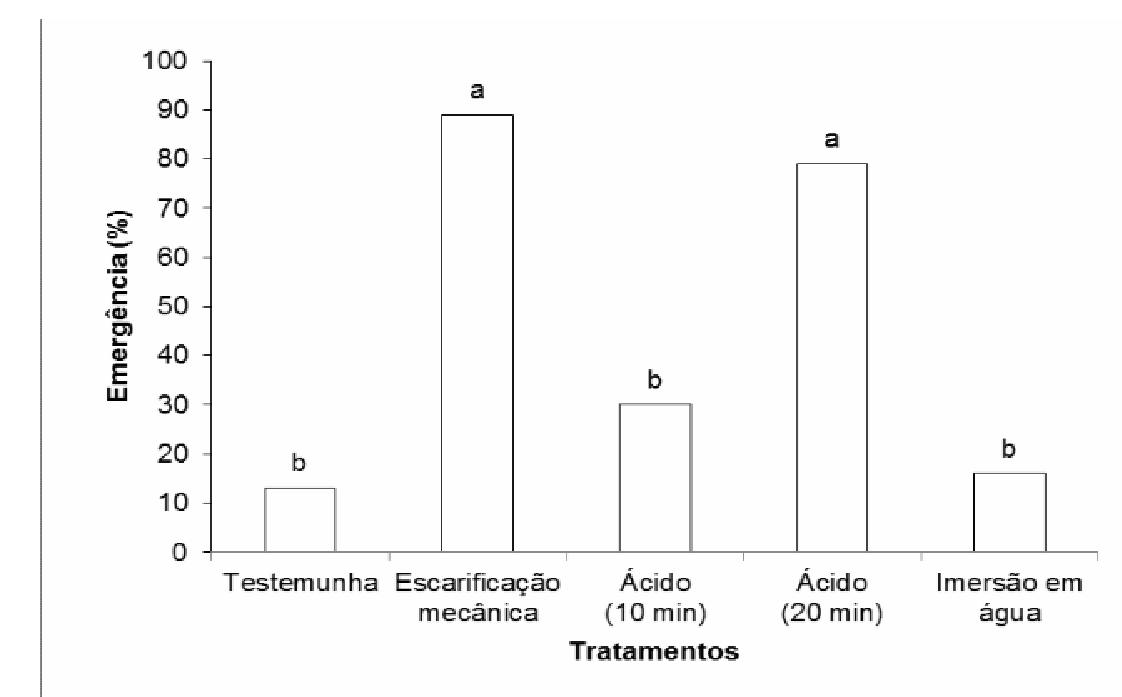

FIGURA 1. Percentagem de emergência de plântulas de $T$. myrmecophila oriundas de sementes submetidas a diferentes tratamentos para a superação de dormência. Médias seguidas pela mesma letra na coluna não diferem entre si pelo teste de Tukey $(p>0,05)$.

A maior parte das sementes do tratamento controle apresentaram-se dormentes durante o experimento, pois não iniciaram o processo de embebição. Sementes que apresentam impermeabilidade do tegumento à absorção de água não mostram nenhum sinal de embebição quando em condições propícias para absorção de água. AGRA et al. (2015) apresentaram resultados que indicam que a dormência tegumentar de sementes da espécie Parkinsonia aculeata $L$. foi superada satisfatoriamente quando foram submetidas à escarificação mecânica com lixa d'água. Já para SHIMIZU et al. (2011) a escarificação com lixa pode ter causado pequenas fragmentações no tegumento das sementes de Schizolobium amazonicum Huber ex Ducke, tornando-o mais permeável ao influxo de água durante a hidratação das sementes. A imersão das sementes em água não foi eficiente em promover a superação da dormência, resultando em apenas $20 \%$ de emergência, sendo assim, pouco efetivo para a superação da dormência das sementes de $T$. myrmecophila.

De acordo com PILON et al. (2012), estudando métodos de quebra de dormência em sementes de Tachigali vulgaris L. G. Silva \& H. C. Lima, o tratamento de imersão em água a temperatura ambiente é pouco eficaz, com baixa porcentagem de sementes germinadas (apenas $5 \%$ ), dessa forma, indesejável para a produção de mudas. A impermeabilidade do tegumento é um dos fatores que afetam a germinação, tornando-se um problema sério, na medida em que impede a entrada de água e oxigênio no interior da semente (CARVALHO \& NAKAGAWA, 2012).

O tratamento com imersão em ácido sulfúrico por 10 minutos resultou em emergência insatisfatória, o que denota que o tempo de escarificação foi insuficiente. Já o tratamento com imersão em ácido sulfúrico por 20 minutos, apresentou maiores valores de emergência, em relação aos demais tratamentos, juntamente com a escarificação mecânica. Corroborando com os resultados do presente trabalho, PEREIRA et al. (2015) encontraram maior porcentagem de emergência em sementes de Pithecellobium dulce (Roxb.) Benth. escarificadas com lixa número 80 ENCICLOPÉDIA BIOSFERA, Centro Científico Conhecer - Goiânia, v.11 n.22; p.2579 2015 
(52\%). GUEDES et al. (2013) obtiveram resultados semelhantes para sementes de Cassia fistula L., que também possuem tegumento impermeável, onde a escarificação com lixa d'água no 80 na região lateral da semente proporcionou a maior emergência de plântulas (94\%), seguido pelo tratamento de escarificação com lixa d'água no 80 e imersão em água por $12 \mathrm{~h}(86 \%)$ e o tratamento de imersão em ácido sulfúrico por 20 minutos (81\%).

Resultados semelhantes também são relatados por PILON et al. (2012), em que, tanto a escarificação química com ácido sulfúrico quanto a escarificação mecânica com lixa resultaram em taxa de germinação superior a $70 \%$. Os tratamentos com imersão em ácido sulfúrico podem ser utilizados para superar a impermeabilidade do tegumento das sementes de T. myrmecophila e, o aumento da emergência por meio da aplicação deste método está relacionado com o aumento do tempo de imersão das sementes no ácido. No entanto, é possível que, se ocorrer um aumento no tempo de imersão das sementes no ácido pode haver danos aos embriões. $O$ ácido sulfúrico pode promover a permeabilidade das sementes sem afetar sua viabilidade quando não atinge regiões abaixo da testa, assim, sem causar danos ao embrião. A escarificação com ácidos foi empregada com eficiência na superação da dormência de sementes de Centrosema plumieri Benth (GAMA et al., 2011) e Sesbania virgata (Cav.) Pers. (SOUZA et al., 2010). SOUZA FILHO et al. (2005), trabalhando com Senna spectabilis (DC) Irwin et Barn. e MEDEIROS FILHO et al. (2005), com Caesalpinia ferrea Mart. ex Tul., encontraram resultados similares em relação ao tempo de exposição ao ácido, onde, quanto maior o tempo de exposição, maior o aumento da taxa de germinação.

AZEREDO et al. (2010) trabalhando com Piptadenia moniliformis Benth, concluíram que os tempos de imersão de 20, 25 e 30 minutos em ácido sulfúrico são recomendados para superação da dormência da espécie, de forma eficiente. MELO et al. (2011), em experimento com sementes de $P$. panurensis e $P$. velutina escarificadas por 30 minutos em ácido sulfúrico, encontraram emergência acima de $80 \%$. Para sementes de Brachiaria humidicola (Rendle) Schweick, que foram armazenadas por 21 meses, o pré-tratamento com imersão em ácido sulfúrico foi efetivo para a superação da dormência (COSTA et al., 2011). Outros autores também constataram a eficiência do ácido sulfúrico na superação da dormência de sementes, como por exemplo, para as espécies Sideroxylon obtusifolium (Roem. \& Schult) T. D. Penn de (REBOUÇAS et al., 2012), flamboyant (MISSIO et al., 2011), Colubrina glandulosa PERK. (GOULART et al., 2011) e Libidibia ferrea (Mart.) L. P. Queiroz (MATOS et al., 2015).

Os maiores índices de velocidade de emergência (IVE) (Figura 2) foram observados quando se utilizou a escarificação com lixa ํㅡ 80 e escarificação química com imersão em ácido sulfúrico por 20 minutos. Constatou-se a eficiência desses tratamentos em superar a dormência das sementes de tachi-preto, de forma que estas puderam expressar de forma mais efetiva o seu potencial fisiológico, em relação aos demais tratamentos, sendo evidenciado pelos maiores valores de IVE. Portanto, os tratamentos proporcionaram maior área de contato para a embebição de água entre a semente e o substrato úmido, o que ocasionou eficiente absorção de água e assegurou os melhores resultados de emergência e velocidade de emergência, podendo ser utilizados na superação da dormência de sementes de $T$. myrmecophila. De acordo com PARREIRA et al. (2012), os maiores índices de velocidade de germinação de sementes de Momordica charantia L. também ocorreram nos tratamentos químicos com ácido sulfúrico. 


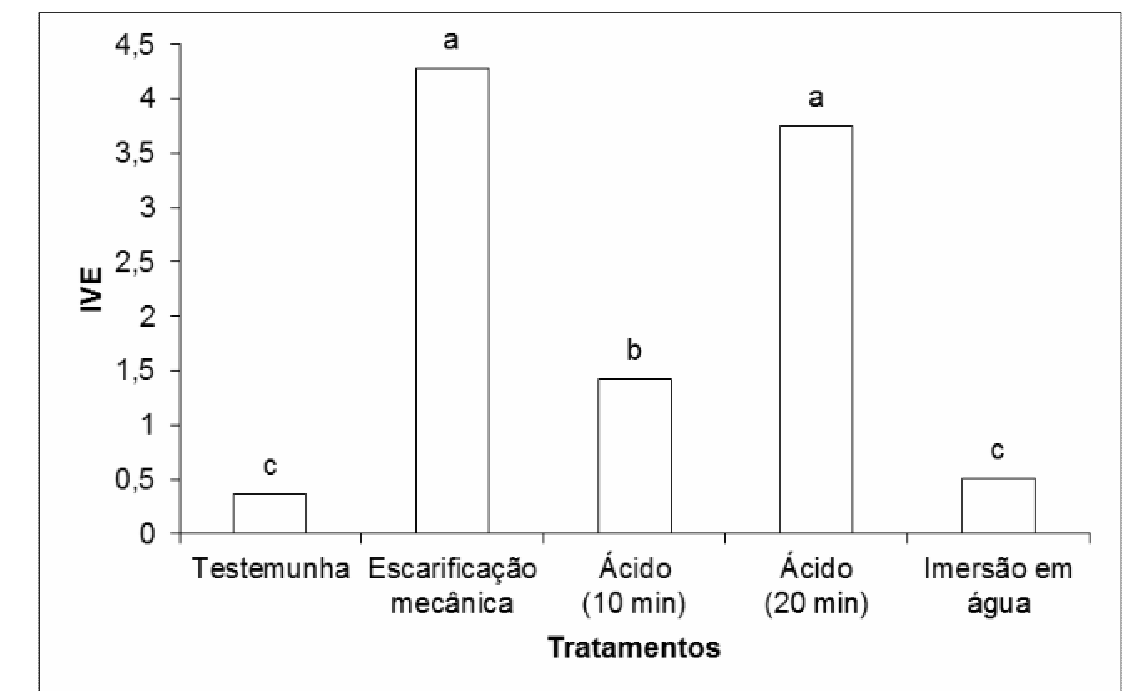

FIGURA 2. Índice de velocidade de germinação (IVG) de plântulas de $T$. oriundas de sementes submetidas a diferentes tratamentos para a superação de dormência. Médias seguidas pela mesma letra na coluna não diferem entre si pelo teste de Tukey $(p>0,05)$.

Para T. myrmecophila, o tratamento que resultou em menor tempo médio de emergência (TME) foi aquele com lixa ํㅡ 80 e ácido sulfúrico por 20 minutos (Figura 3), que obtiveram menor tempo de emergência e maior número de plântulas emergidas. Ainda, na Figura 3, é possível verificar que a imersão em ácido por 10 minutos apresentou maior TME, ou seja, ficou comprovado a necessidade de um tempo maior que 10 minutos para que ocorra a superação tegumentar de forma uniforme. O tratamento com ácido por 20 minutos não apresentou diferença estatística quando comparado a escarificação com lixa. PEREIRA \& FERREIRA (2010), quando utilizaram escarificação com lixa no lado distal em sementes de Parkia discolor Spruce ex Benth., obtiveram germinação e tempo médio de germinação de $99 \%$ e 4,3 dias, respectivamente.

De acordo com DAPONT et al. (2014), avaliando a superação de dormência em sementes de Schizolobium amazonicum Huber ex Ducke, nos tratamentos com lixa e punção as primeiras plântulas emergiram aos nove dias, com TME/Nt (tempo médio de emergência/número total) de 11,1/85 e 10,4/89, respectivamente. Em estudo de PEREIRA et al. (2015), os melhores resultados de TME foram encontrados para os tratamentos com escarificação mecânica com lixa $n^{\circ} 80 \mathrm{e}$ embebição em água à temperatura ambiente durante 48 horas, com valores estatisticamente iguais. SANTOS et al. (2014) constatou que a escarificação química por meio do ácido sulfúrico em sementes de Piptadenia viridiflora (Kunth) Benth promoveu a elevação das taxas de emergência e redução dos valores do TME quando expostas ao ácido por 22 minutos. 


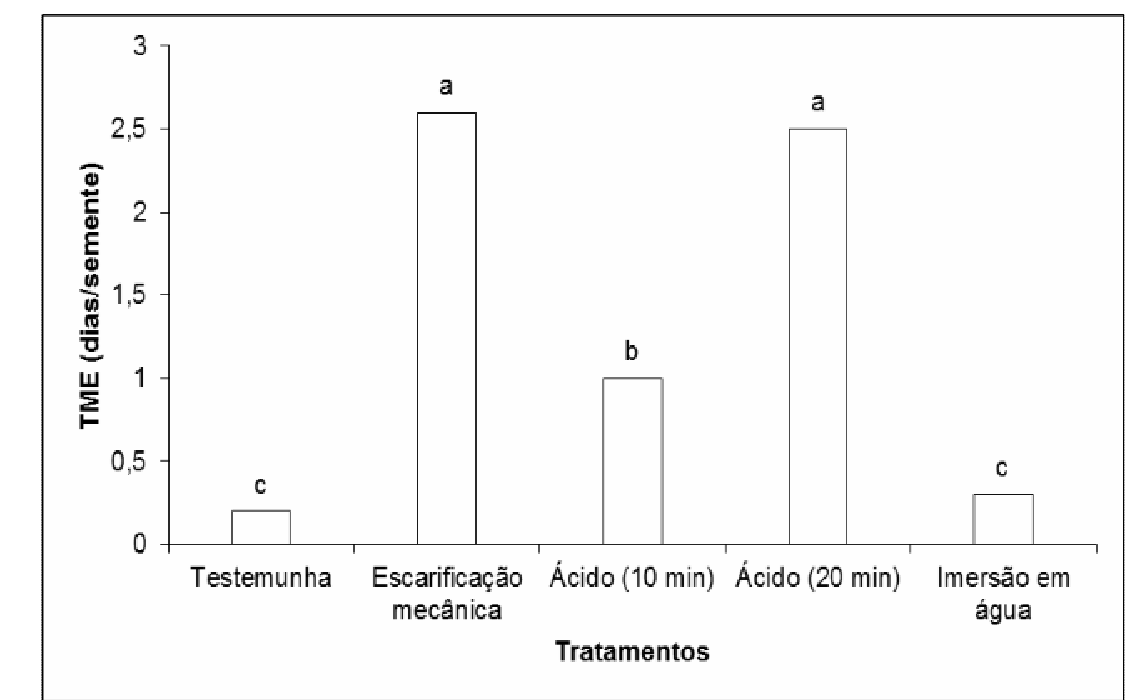

FIGURA 3 - Tempo médio de emergência de plântulas de $T$. myrmecophila oriundas de sementes submetidas a diferentes tratamentos para a superação de dormência. Médias seguidas pela mesma letra na coluna não diferem entre si pelo teste de Tukey $(p>0,05)$.

As sementes submetidas à escarificação mecânica obtiveram maior comprimento médio de raiz principal $(\mathrm{CR})$ e de parte aérea (CPA) das plântulas (Figura 4). Os tratamentos de escarificação química por 10 e 20 minutos não apresentaram diferença significativa em relação ao comprimento da parte aérea. Em relação ao comprimento da raiz principal, os valores foram significativos, com maior média alcançada pelo tratamento de escarificação mecânica. $\mathrm{Na}$ espécie Sideroxylon obtusifolium (Roem. \& Schult.) T. D. Penn., a escarificação das sementes com lixa no 50, sem embebição, propiciou maior comprimento da raiz primária de suas plântulas (REBOUÇAS et al., 2012). Contrastando com os resultados do presente trabalho, de acordo com AVELINO et al. (2012) o maior comprimento da raiz principal das plântulas de Caesalpinia ferrea Mart. ex Tul. var. ferrea foi obtido com sementes não escarificadas.

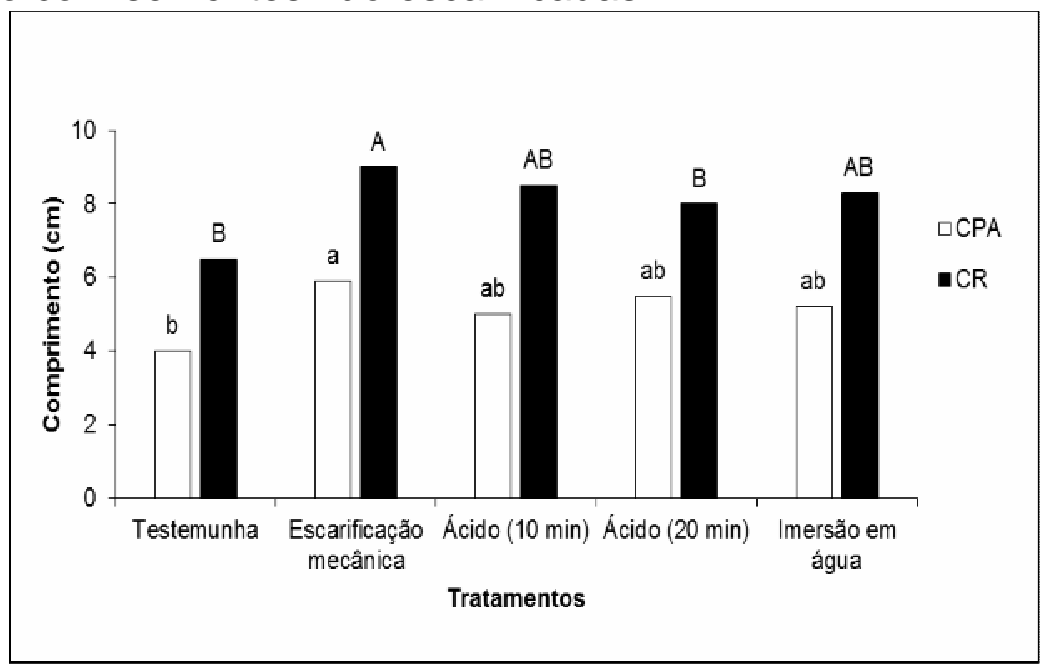

FIGURA 4. Comprimento de parte aérea (CPA) e comprimento da raiz principal (CRP) de plântulas de T. myrmecophila oriundas de sementes submetidas a diferentes tratamentos para a superação de dormência. Médias seguidas pela mesma letra na coluna, considerando-se a mesma variável, não diferem entre si pelo teste de Tukey $(p>0,05)$. 
A alocação de massa de matéria seca (g) também foi influenciada pelos tratamentos (Figura 5). As sementes não tratadas (testemunha), imersas em ácido por 10 minutos e imersas em água por 24 horas apresentaram valores inferiores, quando comparados aos dois melhores tratamentos (escarificação mecânica e imersão em ácido por 20 minutos), para alocação de massa de matéria seca na parte aérea e raiz. A massa de matéria seca da raiz primária dos tratamentos com lixa e ácido por 20 minutos não diferiram entre si, entretanto obtiveram os melhores resultados quando comparados aos demais tratamentos. GAMA et al. (2011) encontraram resultados similares de massa de matéria seca das raízes e da parte aérea de plântulas da espécie Centrosema plumieri BENTH., com os tratamentos de imersão em ácido sulfúrico concentrado durante $9,20,40$ e 50 minutos e escarificação com lixa sem imersão em água, que proporcionaram os maiores valores. Diferentemente dos resultados obtidos no presente trabalho, FERREIRA et al. (2014) demonstram que o tratamento que proporcionou maior acúmulo de massa de matéria seca do sistema radicular das plântulas de Poincianella bracteosa (Tul.) L. P. Queiroz foi aquele com sementes não escarificadas.

Segundo OLIVEIRA et al., (2012), a massa de matéria seca foi influenciada por tratamentos com ácido (30 e 40 minutos), sendo eficazes na superação da dormência das sementes de $P$. gigantocarpa, proporcionando maior vigor na germinação e maiores médias de alocação de massa de matéria seca na raiz primária. AVELINO et al. (2012) observaram que a escarificação mecânica e química, mais 24 horas de embebição em água, destacam-se como os tratamentos mais promissores ao acúmulo de massa de matéria seca de plântulas de Caesalpinia ferrea Mart. ex Tul. var. ferrea. Ao contrário de GUEDES et al., (2009), que observaram que o tratamento de imersão em ácido sulfúrico por 12 minutos originou plântulas com maior conteúdo de massa de matéria seca, enquanto os tratamentos com escarificação mecânica manual com lixa d'água no 80 , por 6 e 9 minutos, seguido de embebição em água, e escarificação mecânica com lixa d'água №. 80, por 3 e 6 min, seguida de embebição $\mathrm{KNO}_{3}$ por $24 \mathrm{~h}$, foram responsáveis pelos menores conteúdos de massa seca de plântulas de Myracrodruon urundeuva Allemão.

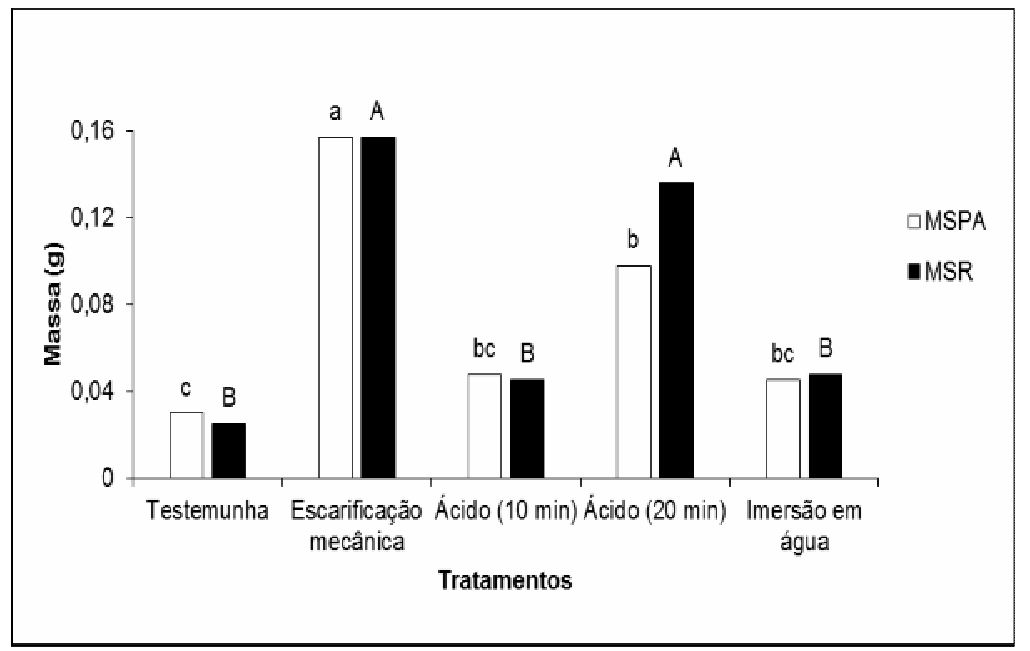

FIGURA 5. Massa de matéria seca de parte aérea (MSPA) e massa de matéria seca radicular (MSR) de plântulas de $T$. myrmecophila oriundas de sementes submetidas a diferentes tratamentos para a superação de dormência. Médias seguidas pela mesma letra na coluna, considerandose a mesma variável, não diferem entre si pelo teste de Tukey $(p>0,05)$. 
A alta porcentagem de sementes duras provenientes dos diferentes tratamentos pré-germinativos (Figura 6) evidencia a baixa eficiência dos tratamentos sem escarificação, imersão em ácido até 10 minutos e imersão em água por 24h. ESCOBAR et al. (2010) apresentam resultados semelhantes relacionadas à sementes de Acacia caven (Mol.) Mol., onde os tratamentos com lixa d'água no 80 até o desgaste visível do tegumento no lado oposto à micrópila e corte de $1,0 \mathrm{~mm}$, com o auxílio de um estilete, na região oposta à micrópila, não obtiveram sementes duras, o que comprova a eficácia dos mesmos na embebição das sementes. A porcentagem de sementes dormentes de Crotalaria juncea $L$ atingiu um máximo de $24 \%$, correspondente ao tempo de armazenamento de 24 meses e para sementes mortas houve maior índice (15,5\%) dentre os lotes avaliados (SILVA et al., 2015).

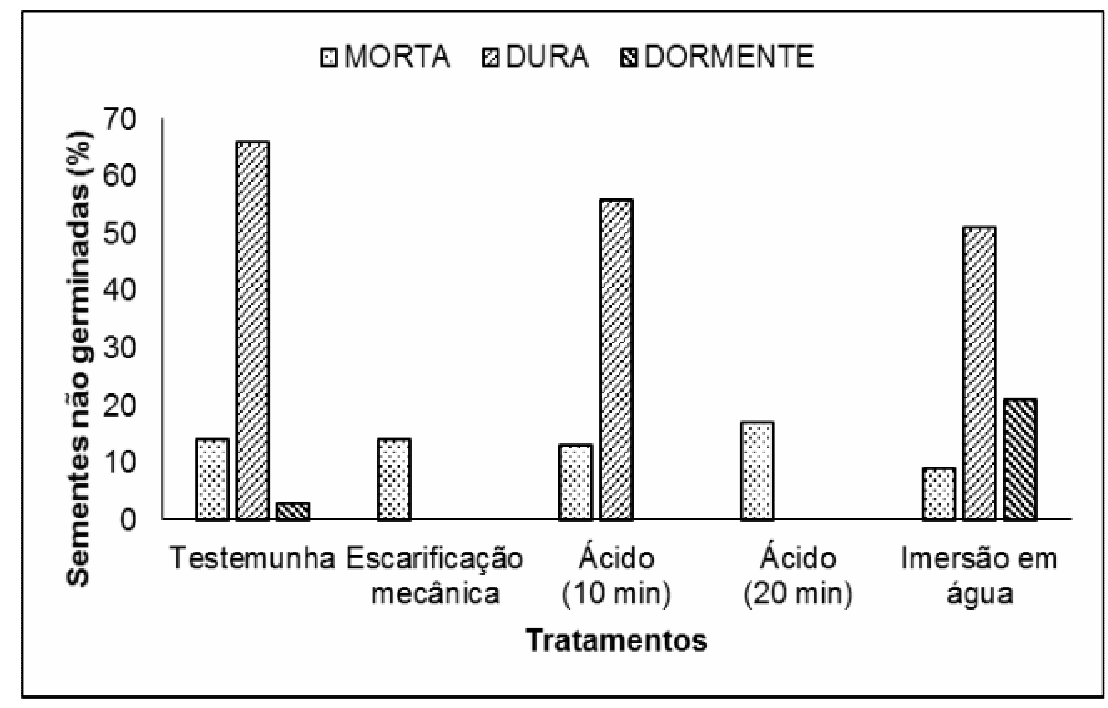

FIGURA 6. Valor percentual das sementes de $T$. myrmecophila que não germinaram após serem submetidas aos cinco diferentes tratamentos.

\section{CONCLUSÃO}

Os tratamentos de escarificação mecânica com lixa ํㅡ 80 e imersão em ácido sulfúrico por 20 minutos proporcionam maior vigor na emergência e crescimento de plântulas.

Para a produção de mudas da espécie, recomenda-se a escarificação mecânica das sementes com lixa, pelo bom resultado de emergência e por dispensar a utilização do ácido sulfúrico.

\section{REFERÊNCIAS}

AGRA, P. F. M.; GUEDES, R. S.; SILVA, M. L. M.; SOUZA, V. C.; ANDRADE, L. A.; ALVES, E. U. Métodos para superação da dormência de sementes de Parkinsonia aculeata L. Semina: Ciências Agrárias, v. 36, n. 3, p. 1191-1202, 2015.

AVELINO, J. I. et al. Métodos de quebra de dormência em sementes de jucá (Caesalpinia ferrea Mart. ex Tul. var. ferrea). Revista Verde, v. 7, n. 1, p. 102-106, 2012. 
AZEREDO, G. A.; PAULA, R. C.; VALERI, S. V.; MORO, F. V. Dormência em sementes de Piptadenia moniliformis benth. Revista Brasileira de Sementes, v. 32, n. 2 p. 049-058, 2010.

BRASIL. Ministério da Agricultura, Pecuária e Abastecimento. Secretaria de Defesa Agropecuária. 2009. Regras para análise de sementes. MAPA/ACS, Brasília, Brasil. 395 p.

CÂMARA, C. de A.; ARAÚJO NETO, J. C. de; FERREIRA, V. M.; ALVES, E. U.; MOURA, F. de B. P. Caracterização morfométrica de frutos e sementes e efeito da temperatura na germinacão de Parkia pendula (willd.) benth. ex walp. Ciência Florestal, v.18, n.3, p.281-290, 2008.

CARVALHO, J. O. P.; SILVA, J. N. M.; LOPES, J. C. A. Growth rate of a terra firme rain forest in Brazilian amazonia over an eight-year period in response to logging. Acta Amazonica, v. 34, n. 2, p. 209- 217, 2004.

CARVALHO, M.N. de; NAKAGAWA, J. Sementes: ciência, tecnologia e produção. 5.ed. Jaboticabal: Funep, 2012. 590p.

COSTA, C. J.; ARAÚJO, R. B.; BÔAS, H. D. C. V. Tratamentos para a superação de dormência em sementes de Brachiaria humidicola (Rendle) Schweick. Pesquisa Agropecuária Tropical, v. 41, n. 4, p. 519-524, 2011.

DAPONT, E. C.; SILVA, J. B.; OLIVEIRA, J. D.; ALVES, C. Z. e DUTRA, A. S. Métodos para acelerar e uniformizar a emergência de plântulas de Schizolobium amazonicum. Revista Ciência Agronômica, Fortaleza, v. 45, n. 3, p. 598-605, 2014.

ESCOBAR, T.A.; PEDROSO, V. M.; BONOW, R. N.; SCHWENGBER, E. B. Superação de dormência e temperaturas para germinação de sementes de Acacia caven (Mol.) Mol. (ESPINILHO). Revista Brasileira de Sementes, vol. 32, n. 2 p. 124-130, 2010.

FERREIRA, E. G. B S.; FERREIRA, E. G. B. S.; MATOS, V.P.; GONÇALVES, E. P.; FERREIRA, R. L. C e SILVA, R. B. Tratamentos pré-germinativos em sementes de duas espécies do gênero Poincianella. Revista Ciência Agronômica, v. 45, n. 3, p. 566-572, 2014.

GAMA, J. S. N.; ALVES, E. U.; BRUNO, R. L. A.; PEREIRA JUNIOR, L. R.; BRAGA JUNIOR, J. B. M.; MONTE, D. M. O. Superação de dormência em sementes de Centrosema plumieri Benth. Revista Brasileira de Sementes, v. 33, n. 4, p. 645653, 2011.

GOULART, P. B.; BRANCALION, P. H. S.; MONDO, V. H. V.; NOVEMBRE, A. D. da L. C. Escarificação química para a superação da dormência de sementes de saguaraji-vermelho (Colubrina glandulosa PERK. RHAMNACEAE). Revista Árvore, v.35, n.1, p.119-124, 2011. 
GUEDES, R. S.; ALVES, E. U.; GONÇALVES, E. P.; COLARES, P. N. Q.; MEDEIROS, M. S. e SILVA, K. B. Tratamentos pré-germinativos em sementes de Myracrodruon urundeuva freire allemão. Revista Árvore, v.33, n.6, p997-1003, 2009.

GUEDES, R. S.; ALVES, E. U.; SANTOS-MOURA, S. S.; COSTA, E. G.; MELO, P. A. F. R. Tratamentos para superar dormência de sementes de Cassia fistula L. Revista Biotemas, v. 26, n. 4, p. 11-22, 2013.

MATOS, A. C. B.; ATAÍDE, G. M.; BORGES, E. E. L. Physiological, physical, and morpho-anatomical changes in Libidibia ferrea ((Mart. ex Tul.) L.P. Queiroz) seeds after overcoming dormancy. Journal of Seed Science, v.37, n.1, p.026-032, 2015.

MEDEIROS FILHO, S.; SILVA, M. A. P. da; SANTOS FILHA, M. E. C. dos. Germinação de sementes e desenvolvimento de plântulas de Caesalpinia ferrea Mart. ex Tul var. ferrea em casa de vegetação e germinador. Revista Ciência Agronômica, v.36, n.2, p.203-208, 2005.

MELO, M. G. G.; MENDONÇA, M. S. P. N.; MENDES, A. M. S. Dormência em sementes de Parkia spp. Revista Brasileira de Sementes, v. 33, n.3 p. 533-542, 2011.

MENDES, A. M. da S.; BASTOS, A. de A.; MELO, M. da G. G. de. Padronização do teste de tetrazólio em sementes de Parkia velutina Benoist (Leguminosae Mimosoideae). Acta Amazônica, v.39, n.4, p.823-828, 2009.

MISSIO E. L.; MAURMANN, R.; TREVISAN, R.; TRENTO, R. Resposta de sementes de Flamboyant submetidas a dois métodos de superação de dormência. Revista da FZVA, v.18, n. 2, p. 46-55. 2011.

OLIVEIRA, A. K. M.; RIBEIRO, J. W. F.; PEREIRA, K. C. L.; RONDON, E. V.; BECKER, T. J. A. BARBOSA; L. A. Superação de dormência em sementes de Parkia gigantocarpa (FABACEAE - MIMOSIDAE). Ciência Florestal, v. 22, n. 3, p. 533-540, 2012.

OLIVEIRA, L.M., DAVIDE, A.C., CARVALHO, M.L.M. Avaliação de métodos para quebra de dormência e para a desinfestação de sementes de Canafístula (Peltophorum dubium (Sprengel) Taubert. Revista Árvore, v.27, n.5, p.597-603, 2003.

PARREIRA, M. C.; CARDOZO, N. P.; PEREIRA, F. C. M.; ALVES, P. L. da C. A. Superação de dormência das sementes e controle químico de Momordica charantia L. Bioscience Journal, v.28, n.3, p.358-365, 2012.

PEREIRA, F. E. C. B.; GUIMARÃES, I. P.; TORRES, S. B.; BENEDITO, C. P. Superação de dormência em sementes de Pithecellobium dulce (Roxb.) Benth. Semina: Ciências Agrárias, v.36, n.1, p. 165-170, 2015.

PEREIRA, S. A.; FERREIRA, S. A. N. Superação de dormência em sementes de visgueiro-do-igapó (Parkia discolor). Acta Amazonica, v.40, n.1, p.151-156, 2010. 
PILON, N.A.L.; MELO, A.C.G.; DURIGAN, G. Comparação de métodos para quebra de dormência das sementes de carvoeiro - Tachigali vulgaris L.F. Gomes da Silva e H.C. Lima (FAMÍLIA: FABACEAE - CAESALPINIOIDEAE) (NOTA CIENTÍFICA 1). Revista do Instituto Florestal, v.24, n.1 p.133-138, 2012.

REBOUÇAS, A. C. M. N.; MATOS, V. P.; FERREIRA, R. L. C.; SENA, L. H. M.; SALES, A; G. F. A. e FERREIRA, E. G. B. S. Metodos para superação da dormência de sementes de quixabeira (Sideroxylon obtusifolium (Roem. \& Schult) T. D. Penn). Ciencia Florestal, v. 22, n. 1, p. 183-192, 2012.

REGO, S.S.; NOGUEIRA, A.C.; KUNIYOSHI, Y.S.; SANTOS, A.F. Germinação de sementes de Blepharocalyx salicifolius (H.B.K.) Berg. Em diferentes substratos e condições de temperaturas, luz e umidade. Revista Brasileira de Sementes, v.31, n.2, p.212-220, 2009.

RIBEIRO, J.E.L.S. et. al., Flora da Reserva Ducke. Guia de Identificação das Plantas Vasculares de uma Floresta de Terra-firme na Amazônia Central, INPADFID, p. 391, 1999.

ROLSTON, M. P. Water impermeable seed dormancy. Botanical Review, v.44, n.3, p. 365-396, 1978.

SANTANA, D. de G.; RANAL, M. A.; Análise da germinação. Um enfoque estatístico. Brasília: Universidade de Brasília, 2004. 248p.

SANTOS, E.C. S.; SOUZA, R. C. R.; BARBOSA, K. H. N.; VASCONCELOS, M. A. Caracterização energética de espécies lenhosas nativas da Amazônia. XXXVI Congresso Brasileiro de Engenharia Agrícola, Bonito - MS, 30-7 a 2-8-2007.

SANTOS, J. L.; LUZ, I. S.; MATSUMOTO, S. N.; D’ARÊDE, L. O.; VIANA, A. E. S. Superação da dormência tegumentar de sementes de Piptadenia viridiflora (Kunth) Benth pela escarificação química. Biosciense Journal,, v.30, n.6, p.1642-1651, 2014.

SHIMIZU, E. S. C. et al. Aspectos fisiológicos da germinação e da qualidade de plântulas de Schizolobium amazonicum em resposta à escarificação das sementes em lixa e água quente. Revista Árvore, v.35, n.4, p.791-800, 2011.

SILVA, A. L. da; DIAS, D. C. F. dos S.; LIMA, L. B. de; MORAIS, G. A. de. Methods for overcoming seed dormancy in Ormosia arborea seeds, characterization and harvest time. Journal of Seed Science, v.36, n.3, p.318-325, 2014.

SILVA, T. C.; ALVES, M. C. S. TEODORO, M. S; LACERDA, M. N. de. Avaliação e potencial fisiológico de sementes de Crotalaria juncea $L$ em três períodos diferentes de armazenamento. ENCICLOPÉDIA BIOSFERA, v.11, n.20, p.40. 2015.

SOUZA FILHO, A. P. S.; LÔBO, L. T.; ARRUDA, M. S. P. Atividade alelopática em folhas de Tachigali myrmecophyla (Leg. - Pap.). Planta Daninha, v. 23, n. 4, p. 557564, 2005. 
SOUZA, V. C.; AGRA, P. F. M.; ANDRADE, L. A.; OLIVEIRA, I. G.; OLIVEIRA, L. S. Germinação de sementes da invasora Sesbania virgata (Cav.) Pers. sob efeito da luz e da temperatura utilizando superação de dormência. Semina: Ciências Agrárias, v. 31, n. 4, p. 889-984, 2010.

VAN DER WERFF. H. A Sinopsis of the genus Tachigali (Leguminosae: Caesalpinioideae) in northern South America. Disponível em: http://www.bioone.org/doi/pdf/10.3100/025.015.0108. Acesso em: 14 de jul. 2015. 